\title{
DIE RELEVANSIE VAN 'N LINGUISTIESE BENADERING TOT \\ DIE ANALISE VAN KLASSIEKE TEKSTE
}

Johan C. Thom en

Pieter G.R. de Villiers

$0 \quad \mathrm{Na}$ 'n paar opmerkings oor die relevansie van algemene taalwetenskap vir die analise van klassieke tekste in die algemeen, sal h konkrete voorbeeld van ' $h$ analise van 'n Griekse teks bespreek word om die relevansie van 'n linguistiese benadering te illustreer.

1 In die algemeen help linguistiek ' $n$ leser om insig te verwerf in sommige van die redes waarom die leser van 'n teks spesifieke gewaarwordinge by die lees daarvan het. Daarbenewens bied linguistiek 'n begrippe-apparaat en ' $n$ metodologie waardeur aangetoon kan word hoedat die ervaring van 'n teks bepaal word deur die verbale struktuur van die teks. Linguistiek bied ook hulp in die oplossing van interpretasieprobleme deur presies aan te toon waarom een struktuur verkieslik is bo ' $n$ ander een. Linguistiek laat die leser van die teks ook sekere vrae oor die taal van die teks stel wat andersins geignoreer sou word (Traugott en Pratt 1980:20). Daarmee word bedoel dat ' $n$ linguistiese analise $h$ wesenlike rol speel by, en as $n$ noodsaaklike stadium beskou word in, die interpretasieproses. Die linguistiese analise het dus nie $\mathrm{n}$ insidentele karakter en word nie bloot op $h$ ad hoc basis geimplimenteer nie. Vanuit 'n linguistiese benadering tot die teks word op dié wyse 'n konsekwente analise van die teks gemak. Met ' $n$ linguistiese benadering word bedoel ' $n$ werkswyse wat die taal as uitdrukkingsvlak van 'n teks as vertrekpunt vir h analise neem. ${ }^{1)}$

2 Onder Suid-Afrikaanse klassici en Nuwe Testamentici is daar al $n$ geruime tyd $\mathrm{n}$ beweging om klassieke tekste met linguistiese middele te bestudeer. Wat klassieke tekste betref, kan onder andere verwys word na die werk van Barkhuizen (1976) en Venter (1981), en vir die Nuwe Testament na Louw (1976 en 1979), Vorster (1979), Combrink (1979) en die bydraes in Neotestamentica 11 ("The structure of Matthew 1-13 --- an exploration into discourse analysis"). Ter illustrasie word Maartens se analise in laasgenoemde bundel van die "Onse Vader"gebed in Matteus 6 bespreek. (Sien Bylae vir Griekse teks.)

3 In sy teoretiese inleiding gee Maartens rekenskap van sowel die sintaktiese eenhede waaruit in teks bestaan as in semantiese representasie van so $\mathrm{n}$ sin. 
3.1 n Omvattende sintaktiese eenheid bestaan uit 'n sin wat nul of meer ingebedde sinne domineer. 'n Sin sou dan in terme van ' $n$ generatiewe model gedefinieer kan word as ' $n$ eenheid wat bestaan uit ' $n$ NP en $h$ VP [S NP VP]. Die eenheid is "sintakties" omdat daarmee verwys word na die lineêre volgorde van konstituente en die hiërargiese verhoudinge in die konstituente-struktuur van die sin (49-50).

3.2 In die semantiese representasie van elke sin van 'n teks sal onder andere die presupposisie, die fokus en topic van elke sin gespesifiseer word. Die presupposisie is die inligting in elke sin wat die skrywer by sy lesers as bekend veronderstel. Die fokus is die (nuwe) inligting wat hy as onbekend veronderstel. Die topic is die semantiese subjek van h sin, dit wil sê die element onder bespreking. Dit hoef nie noodwendig die grammatikale funksie van subjek in die dieptestruktuur van 'n sin te hê nie. In die geval van klassieke Griekse tekste kan die topic beklemtoon word deur ' $\mathrm{n}$ sinsinisiële of sinsfinale posisie. Die sintaktiese meganisme waardeur 'n woord in 'n sinsinisiële of sinsfinale posisie geplaas word, word "topikalisering" genoem (50).

3.3 Intersin-struktuur: In 'n analise van 'n teks beweeg die leser oor die grens van die sin om die struktuur van 'n groter eenheid wat bestaan uit $n$ versameling sinne, te ondersoek. Die cluster is $h$ omvattende semantiese eenheid. Hierdie groep sinne vertoon $\mathrm{n}$ kohesie rondom $h$ fokussin en staan in $n$ wederkerige verhouding tot mekaar in 'n spesifieke volgorde om die fokussin(ne). Die struktuur tussen sinne behels die lineêre volgorde van sinne en die hiërargiese verhoudinge tussen sinne in die groep. Sodra die leser oor die grens van die sin beweeg, is hy volgens Maartens besig met $n$ literatuurwetenskaplike ondersoek en nie meer met 'n linguistiese analise nie (51). Met hierdie onderskeid kort hy die relevansie van ' $\mathrm{n}$ linguistiese benadering tot die analise van tekste onnodig in, aangesien linguistiek volgens ons wel deeglik 'n bydrae te lewer het tot die bestudering van groter eenhede as die sin ( $\mathrm{vg} 1$. ook Traugott en Pratt 1980:20).

4 In sy analise van Matteus 6 wys Maartens op die kenmerkende sintaktiese struktuur van hierdie gedeelte en kom tot die gevolgtrekking dat dit bewerkstellig is deur middel van foregrounding wat hy voorlopig as die doelbewuste beklemtoning van sinskonstituente beskryf $(51-54)$.

4.1 Vervolgens word h deel van sy analise van Matteus 6, naamlik die gedeelte oor die Onse Vader, bespreek om aan te toon wat die implikasies van sy linguistiese benadering vir die verstaan van die teks is. Die gebed word ingelei deur 'n opdrag van Jesus: "So moet julle bid". Volgens Maartens vind foregrounding plaas op di.e bywoord "só" deur dit na die sinsinisiële posisie te skuif. Dit beklemtoon die opsionaliteit van die paradigma wat volg: dit is nie bedoel om noodwendig verbatim herhaal te word nie. Reeds ten opsigte 
van hierdie opmerkings van Maartens, kan met hom in debat getree word. In die Grieks word die "julle" veel eerder beklemtoon, omdat dit (a) eksplisiet in die sin voorkom (normalweg word dit slegs morfologies aangedui deur die persoonsuitgang van die werkwoord) en (b) in die sinsfinale posisie staan. Hierdeur word die wyse waarop die dissipels moet bid, in onderskeid met die gebede van die geveinsdes en die heidene, beklemtoon.

Op formele vlak kan volgens Maartens twee hegte strukturele eenhede onderskei word in die modelgebed. E1ke eenheid bevat op sy beurt drie bedes. As subjek-NP het die bedes: "onse Vader wat in die heme1 is". Verder word die bedes deur h vergelyking simmetries in twee dele verdeel naamlik die "U"-gebede en' die "ons"-gebede. Maartens noem net die feit dat hierdie subjek-NP teenwoordig is in die dieptestruktuur van al ses bedes. ' $n$ Mens sou egter verder kon gaan deur daarop te wys dat hierdie feit, sowel as die dominante posisie van die subjek-NP aan die begin van die gebed, $h$ belangrike bydrae lewer tot die kohesie van die gebed.

4.1.1 Die "U"-gebede. In die wyer simmetriese struktuur word die eerste drie bedes in $h$ vaste eenheid saamgebind. Dit kan as "U"-gebede beskryf word. Die "U" word in die Griekse teks deur foregrounding beklemtoon deur dit in die sinsfinale posisie te plaas en andersyds deur dit drievoudig te herhaal. Die sinskonstituente van die eerste drie bedes word "gekoppel" in sintagmaties ekwivalente posisies. Die 3 strofes wat uit 9 sillabes bestaan is nie net semanties ekwivalent nie, maar ook metries ekwivalent. Ook in hierdie geval kan gewys word op die bydrae wat bogenoemde ekwivalensies wat Martens aanwys, lewer tot die kohesie van die teks.

Daar is, volgens Maartens, $h$ intensifisering in die lineêre ontwikkeling van die topic: die topic word geintensifiseer van die heiliging van God se naam na die koninkryk en uiteindelik na die wil van God. Die ondergeskikte frase soos op die aarde so ook in die hemel, is net soos die subjek-NP, anwesig in die dieptestruktuur van die bedes, en omdat dit beskikbaar is vir die semantiese komponent, word dit daarom voorveronderstel in elkeen van die bedes. Hierdie ondergeskikte frase behels die gebed dat God die verskil tussen hemel en aarde moet uitwis en met die koninkryk die temporele en ruimtelike bestaan van die wêreld moet binnedring. Daar kan egter hier teenoor Maartens 'n saak daarvoor uitgemaak word dat daar nie 'n lineêre ontwikkeling van die topic in die triplet is nie, maar dat die middelste van die drie bedes beklemtoon word. Dit blyk uit die feit dat in hierdie bede die werkwoord nie $h$ passief is soos in die eerste en derde gebed nie. So $\mathrm{h}$ interpretasie sou ook ooreenstem met sy eie formulering dat dit die koninkryk is wat na hierdie wêreld moet deurbreek. Van belang is egter om daarop te let dat, anders as Maartens, ons interpretasie met linguistiese argumente beredeneer kan word. 
4.1.2 Die "ons"-gebede. Die laaste bedes vorm volgens Maartens drie sinonieme parallelismes wat as volg voorgestel kan word:

1. Die brood van ons die daaglikse

Gee vir ons vandag

2. En vergewe ons ons skulde

Soos ook ons ons skuldenaars vergewe

3. En lei ons nie in versoeking

Maar verlos ons van die bose.

In die uitleggeskiedenis was daar heelwat besprekings oor die betekenis van die byvoeglike naamwoord epiousion by brood. Hoofsaaklik twee interpretasies, wat samhang met die afleidingsgeskiedenis van die woord, word gegee: dit kan of "daaglikse" of "toekomstige" (vir die volgende dag) beteken. Op grond van die sintagmatiese ekwivalente posisies van epiousion en vandag in die parallelisme, sou $h$ mens geneig wees om in semantiese ooreenkoms tussen hulle te wil sien. Op grond hiervan sou "daagliks" verkieslik bo "toekomstig" wees.

Die bede om vergifnis verkry, volgens Maartens, reliëf deur die sentrale posisie waarin dit geplaas is. Teenoor Maartens kan daar opgemerk word dat die blote feit dat die bede die middelste van drie is, nie noodwendig beteken dat dit sterker klem kry nie.

Die struktuur van die laaste bede kan origens ook lig werp op die interpretasie van $Z e i$ in "lei ons nie in versoeking" en bose in "verlos ons van die bose". Een van die probleme in die navorsingsgeskiedenis van die gedeelte was die vraag of dit God is wat die mens in versoeking lei. Binne die raamwerk van h parallelisme word 'n koppeling bewerkstellig tussen onder andere "moenie lei nie" en "verlos". Die semantiese waarde van "moenie lei nie" is gevolglik nader bepaal deur sy verwantskap met "verlos", dit is, "stel ons nie bloot aan versoeking nie" (in plaas van "moenie ons lei nie"). Dit kan selfs positief vertaal word as "bewaar ons van versoeking en bevry ons van die boosheid". Die PP "in versoeking" word semanties deur die koppeling met die PP "van die bose" in verhouding geplaas. "Bose" kan òf onsydig òf manlik wees. Die foregrounding wat plaasvind deur die sintagmaties ekwivalente posisies van hierdie frases, lei ook tot die semantiese verwantskappe tussen beide frases en dui dus op die onsydigheid van "bose" (dit wil sê boosheid).

5 Vervolgens ' $n$ paar opmerkings wat enersyds na aanleiding van Maartens se analise gemaak word, en andersyds betrekking het op klassieke tekste in die algemeen. (Met klassieke tekste word in die eerste plek na Griekse en Latynse tekste verwys, maar die opmerkings sou ook geld vir byvoorbeeld Hebreeuse tekste.) 
5.1 Een van die belangrikste probleme by die gebruikmaking van taalwetenskaplike beginsels in die interpretasie van klassieke tekste, is die feit dat daar betreklik min studies oor die klassieke tale bestaan vanuit $h$ moderne linguistiese perspektief. Daar bestaan byvoorbeeld min linguistiese beskrywings van die Griekse sintaksis waarvan gebruik gemaak kan word in die bestudering van tekste. Maartens makk onder andere van die begrip 'sintaktiese afwyking' gebruik in sy beskrywing van die verskynsel "foregrounding". Die sintaktiese norm wat as basis vir die 'afwyking' funksioneer, is egter nog nie adekwaat beskryf nie. Die klassikus moet dus algemeen taalwetenskaplike beginsels probeer toepas op tale waarin daar nog relatief min grondwerk gedoen is.2)

Miskien belangriker is $h$ probleem wat ten nouste aan die eerste verwant is, naamlik die feit dat klassici nie oor 'n moedertaalkennis van Grieks of Latyn beskik nie, en ook nie toegang het tot moedertaalsprekers nie. Ons beskik oor uiters min voorbeelde van die intuitiewe oordele van die alledaagse spreektaal uit die antieke tyd.

Die kombinasie van hierdie twee "leemtes" in ons ervaring maak dit uiters moeilik om presies te bepaal wat die effek van h bepaalde taalstruktuur in 'n teks op 'n oorspronklike moedertaalleser sou wees.

'n Derde verleentheid ten aansien van klassieke tekste 1ê op die vlak van die pragmatiek. Ons kennis van die sosio-historiese konteks van die meeste klassieke tekste is, om die minste te sê, gebrekkig. Hierdie feit lewer heelwat probleme op vir die interpretasie van pragmatiese verskynsels soos ironie en ander indirekte uitdrukkingswyses.

Ten spyte van bogenoemde drie aporieë, en miskien juis as gevolg daarvan, kan ' $h$ eksplisiete en ' $n$ gefundeerde linguistiese benadering van klassieke tekste veel daartoe bydra om die interpretasie van hierdie tekste op 'n meer kontroleerbare basis te plaas en om dus h meer intersubjektiewe karakter daaraan te gee.

\subsection{Uit die analise blyk duidelik dat kohesie in die teks in 'n} groot mate deur linguistiese middele bewerkstellig word.

'n Linguistiese benadering kan dus ' $n$ belangrike bydrae lewer tot ons verstaan van die wyse waarop ' $n$ teks tot 'n koherente geheel saamgebind word. Een van die wyses waarop kohesie 3 ) tot stand kom, is deur die herhaling van ekwivalente strukture op verskillende vlakke (fonologies, morfologies, sintakties, semanties). Hierdie verskynsel is deur Jakobson beskryf in sy befaamde uitspraak dat "the poetic function projects the principle of equivalence from the axis of selection unto the axis of combination". Die herhaling van linguisties ekwivalente strukture het dus nie net 'n estetiese funksie nie, maar 1ê ook beduidende semantiese relasies (vg1. ook Jakobson 1960).

Omdat klassieke tekste altyd hardop gelees is, behoort fonologiese 
strukture $h$ groter bydrae te lewer tot die totale betekenis en effek van so ' $n$ teks as wat by moderne tekste die geval is. 'n Linguistiese benadering is essensieel vir $n$ adekwate beskrywing en verklaring van hierdie effek.

5.3 Een van die aannames waarop Martens se analise berus, is dat daar $h$ isomorfie bestaan tussen die struktuur van $h$ sin en die struktuur van ' $h$ singroep. Net soos $h$ sin uit $h$ lineêre opeenvolging van konstituente wat hiërargies georden is, bestaan, kan $n$ singroep ook beskryf word as h lineêre opeenvolging van sinne waartussen daar hiërargiese relasies bestaan. Alhoewel Maartens dit nie noem nie, sou $h$ mens kon beweer dat $h$ teks as geheel op dieselfde wyse gestruktureer is: dit is namlik $n$ geheel van eenhede wat mekaar lineêr opvolg en hiërargies georden is. Die feit van so h isomorfie tussen sin en teks is een van die basisaannames van h tekslinguistiek. Dit lyk dus noodsaaklik om 'n linguistiese benadering van tekste te beoefen vanuit $n$ breër tekslinguistiese perspektief.4)

5.4 Om onder andere $\mathrm{h}$ eklektisisme en $\mathrm{n}$ metodiese pluralisme te vermy, is die ontwerp van h koherente en adekwate tekslinguistiese model onontbeerlik. Sodanige modelle bestaan reeds ook vir klassieke tekste (vg1. Hellholm 1980 en 1982). Daar is egter ' $\mathrm{n}$ behoefte aan ' $n$ voortgaande metateoretiese besinning oor die wetenskapsfilosofiese basis van hierdie modelle. Ook hier sou sinvol kers opgesteek kon word by wat reeds in hierdie verband binne die raamwerk van Algemene Taalwetenskap gedoen is (vg1. byvoorbeeld Botha 1978). 


\section{VOETNOTE}

1. Hier word gedink aan die bekende onderskeid van Hjelmslev tussen die uitdrukkingsvlak ("expression") en die inhoudsvlak ("content") van h teken. In die geval van h literêre teks het ons te make met $h$ sekondêre tekensisteem waarvan die taal as primêre tekensisteem die uitdrukkingsvlak vorm. Die inhoudsvlak behels die "ideologie" of "betekenis" van die teks. Vg1. ook Barthes. 1967:89 e.v.

2. As voorbeeld van so $h$ beskrywing, kan verwys word na $h$ artikel oor Egiptiese werkwoordsinne, waarin Janet $\mathrm{H}$. Johnson aangetoon het dat in TG-ondersoek van geskrewe grammatikale vorme in Egiptiese tekste aanwys dat die tradisionele taksonomiese gramatika se driedelíng van soorte sinne in Egipties die ooreenkomste tussen twee van die drie soorte oor die hoof sien: ten spyte van uiteenlopende oppervlaktevorme van sinne met bywoordelike predikate en verbale sinne, is hulle onderliggende organisasie dieselfde. Johnson maak aanspraak daarop dat sy deur $h$ deskriptiewe formele apparaat van onderliggende struktuur, oppervlaktevorme en reëls wat die een met die ander in verhouding plaas, insigte in Egiptiese grammatika verwerf wat korrespondeer met intuïsies oor betekenís (Johnson 1978:5) en wat die duidelikste verklaring bied van die verhoudinge wat deur $n$ moedertaalspreker intuïtief aangevoel word.

3. Lyons makk $h$ onderskeid tussen die "cohesion" en die "coherence" van $h$ teks. Eersgenoemde behels die wyse waarop binding bewerkstellig word, terwyl laasgenoemde na die betekenis-samehang verwys: "Roughly speaking, it (= the distinction between cohesion and coherence) has to do with the difference between form and content .... Ellipsis and the use of pronouns, as well as the use of particular connecting particles and conjunctions (therefore, so, etc.) commonly serve to create and sustain that kind of connectedness to which the term 'cohesion' is applied .... The other kind of connectedness --_ coherence --- is a matter of content, rather than form. In default of any contextual indication to the contrary, what is being said in any one text-unit is as sumed to be relevant to what has just been said in the immediately preceding text-units" (1981:198 e.v.).

4. Vir resente voorbeelde van koherente teorievorming op tekslinguistiese basis, vgl. Gülich en Raible 1977 , wat ten opsigte van Hellenistiese tekste verder gevoer is deur Hellholm 1980 en 1982 . 
http://spilplus.journals.ac.za/

BYLAE

GRIEKSE TEKS VAN DIE "ONSE VADER"-GEBED

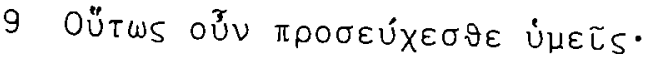

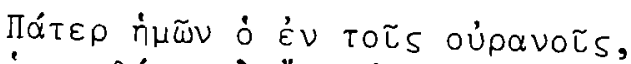

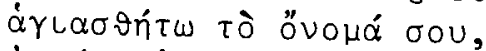

$10 \dot{\varepsilon} \lambda \vartheta \varepsilon \dot{\tau} \tau \dot{\eta} \dot{\eta} \beta \alpha \sigma \lambda \varepsilon \varepsilon \dot{L} \alpha$ oOU,

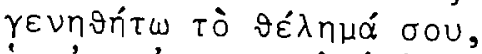

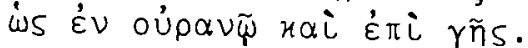

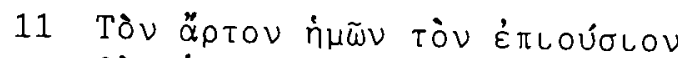

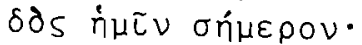

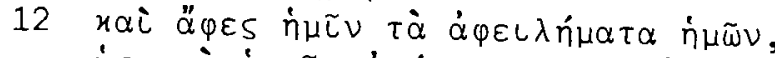

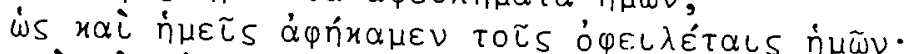

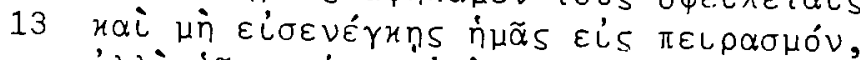

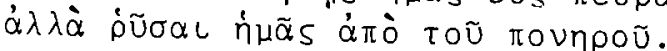


BIBLIOGRAFIE

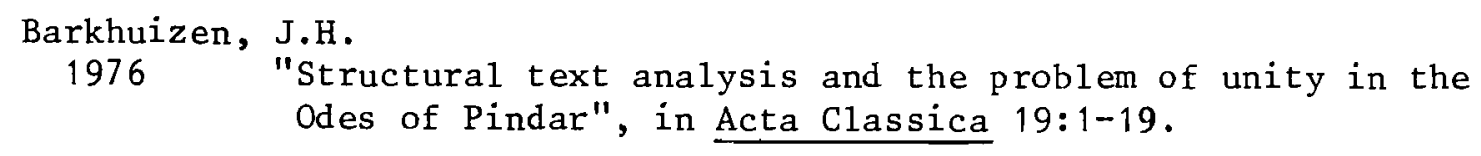




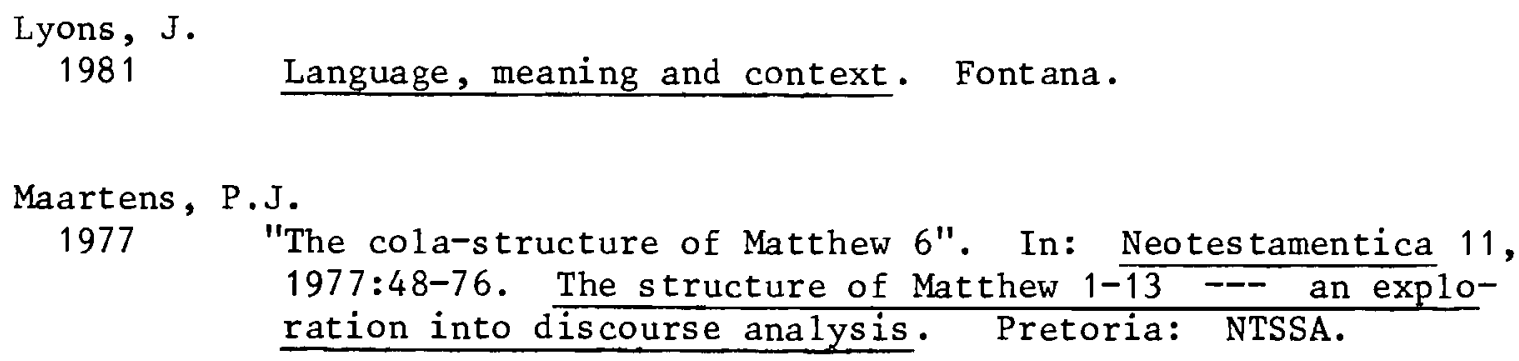

Traugott, E.C. and M.L. Pratt

1980 Linguistics for students of Literature. New York: Harcourt Brace Jovanovich.

Venter, I.J.M.

1981 ' $n$ Semiolinguistiese ondersoek na die Himne aan Aphrodite. Stellenbosch: Ongepubliseerde D.Litt-tesis.

Vorster, W.S.

1979 Aischunomai en stamverwante woorde in die Nuwe Testament. Pretoria: Universiteit van Suid-Afrika. 